\title{
EAl Endorsed Transactions

\section{Performance Analysis of Fractional Earthworm Optimization Algorithm for Optimal Routing in Wireless Sensor Networks}

\author{
Venkat Rao Pasupuleti ${ }^{1, *}$, Ch. Balaswamy ${ }^{2}$ \\ ${ }^{1}$ Department of Electronics and Communication Engineering, Lakireddy Bali Reddy College of Engineering, India. \\ ${ }^{2}$ Department of ECE, Gudlavalleru Engineering College, Gudlavalleru, India.
}

\begin{abstract}
In Wireless Sensor Networks (WSNs), the data transmission from the sensing node to the sink node consumes a lot of energy as the number of communications increases, so the battery life of nodes is limited, and the network also has a limited lifetime. Recent studies show that the bio-inspired meta-heuristic algorithms for solving engineering problems such as energy reduction in autonomous networks in the multidisciplinary areas of WSN, Internet of Things (IoT) and Machine learning models. Hence to increase Network lifetime, optimized clustering and energy-efficient routing techniques are required. In all applications of WSN, not only energy-efficient but also delay and throughput of the network are important for efficient transmission of data to the destination. This paper analyses optimized clustering by selecting cluster heads based on fractional calculus earthworm optimization algorithm (FEWA). The route from cluster heads to sink node is selected based on the fit factor. This paper's main intention is to provide an extensive comparative study of the FEWA with all standard optimization-based clustering and routing techniques. This method's performance is compared with existing optimized clustering methods like GA, PSO, ACO, DE and EWO in terms of the number of energy, delay, and throughput. At the end of 1000 iterations, the analysis shows that the FEWA outperforms existing methods with maximum average remaining energy of the nodes as $0.216 \mathrm{~J}$, the minimum average delay of $0.208 \mathrm{sec}$ and maximum average throughput of $88.57 \%$ for 100 nodes.
\end{abstract}

Keywords: clustering, routing, optimization, earthworm optimization algorithm, fractional calculus.

Received on 01 February 2021, accepted on 06 April 2021, published on 21 April 2021

Copyright (C) 2021 Venkat Rao Pasupuleti et al., licensed to EAI. This is an open access article distributed under the terms of the Creative Commons Attribution license, which permits unlimited use, distribution and reproduction in any medium so long as the original work is properly cited.

doi: 10.4108/eai.21-4-2021.169419

*Corresponding author. E-mail address: venkat2k15@gmail.com

\section{Introduction}

WSN finds various applications in gathering environmental data and solving real-world data gathering problems [1]. To boost the battery life of the network, efficient data aggregation procedures are required. Clustering is a data aggregation approach that enables a network's energy efficiency to achieve efficient transmission, load balance, and scalability. Many clustering algorithms exist in the literature, and very few concentrates on optimizing the necessary WSN constraints. Optimization algorithms are iterative-based approaches used to achieve the desired solution problem outcome. It gives an optimum solution because it is minimized or maximized using one of the many optimization routines. Fractional calculus in engineering applications has been one of the most useful tools recently. It is an analysis of differential problems as fractional derivatives from mathematical calculus. The function of fractional calculation in different fields, such as mechanics, electricity, chemistry, biology, economy, notably control theory, and signal and image processing, has been very significant in recent years [2]. New trending approaches used to optimize engineering problems are bio-inspired methods of optimization. Clustering approaches on wireless sensor networks focused on optimization have brought promising advances over conventional clustering algorithms. This paper uses a newly developed bio-inspired optimization method for cluster head selection, called the FEWA algorithm [3]. 
Using the fractional calculus to solve the optimization problem increases algorithm efficiency by preserving the past background of solutions by choosing the solution equation's proper value for the fractional-order derivative. This paper mainly focuses on comparative analysis of the FEWA algorithm with traditional bio-inspired optimization-based clustering algorithms in WSNs.

The FEWA consists of incorporating a fractional definition into EWA to formulate the $\mathrm{CH}$ selection by the established algorithm. This algorithm records the best $\mathrm{CH}$ in the previous iterations and formulates the efficient $\mathrm{CH}$ of the current iteration with fitness based on energy, trust, and distance. The clustering methods used in WSN are focused mainly on saving and/or enhancing energyrelated lifetimes. Data must also be transmitted via multihop communication to the sink node by selecting the most efficient cluster heads. Therefore, the task is to use data aggregation methods such as clustering in terms of energy, distance, and trust and collection of clusters head employing an effective algorithm for optimization. The selection of intermediate $\mathrm{CHs}$ based on necessary factors based on WSN restrictions must be made for multi-hop communication from the head to the cluster's sink node. This paper's main objective is to explore the performance analysis and comparative study of the FEWA algorithm with other optimization techniques in the literature regarding the delay, energy, and throughput.

\section{Literature Review}

This section provides an overview of WSN applications and several existing energy-efficient and optimized routing techniques to improve the network's lifetime. In [4], the authors provided an extensive review on network layer-based energy-efficient routing techniques related to both WSNs and the Internet of Things (IoT). Bio-inspired meta-heuristic solutions for engineering problems are dominant multidisciplinary research in recent years. Different categorization and detailed analysis of natureinspired algorithms [5] have been explored in disease diagnosis with different data sets [28-34]. There are numerous applications of the nature-inspired optimization algorithms in different areas viz. disease diagnosis, query optimization, sentiment analysis, feature selection, routing, power management, load balancing etc. In cardiac arrhythmia disease analysis, swarm intelligencebased optimization methods [6] have been used to find the optimal values of the feature set for the diagnosis with standard benchmark UCI data set. Sharma, Manik, et al. [7] proposed an entropy-based genetic algorithm to optimize query execution plan in distributed database systems in terms of system size and query complexity. Prableen Kaur and Manik Sharma [8] have provided an extensive review of soft computing-based optimization algorithms for diabetes pre-processing and diagnosis [3541]. Also, the rate of accuracy is analyzed in detail for data mining and hybrid optimization techniques [42-46].
In recent days, most researchers have focused their study on novel coronavirus (Covid-19). Nature-inspired optimization techniques are also used to detect Covid-19 cases and contact tracing [9]. Rachhpal Singh [10] proposed a hybrid MPG optimization algorithm with PSO and GA to feature gene expression. With this method, data dimension and duplication among the classified sets have been reduced significantly [47-51]. Nature-inspired optimization algorithm based on PSO is used for E-health services in Job scheduling on mobile competitive cloud distributed systems [11]. Samriti [12] provided a brief study of the Genetic Algorithm (GA) role in software engineering, distributed computing, and machine learning applications. Few existing $\mathrm{CH}$ collection and routing approaches in WSNs are provided below table and the merits and challenges. Data correspondence from $\mathrm{CH}$ to sink node is direct in many cluster-based literary algorithms [23-27]. The FEWA algorithm optimizes the selection of the route from $\mathrm{CH}$ to the sink node for multihop communication.

Table 1. Review of existing methods

\begin{tabular}{|c|c|c|c|c|}
\hline 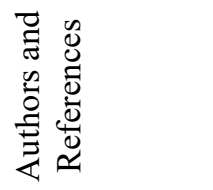 & 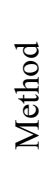 & 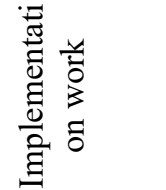 & 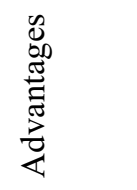 & .气 \\
\hline $\begin{array}{l}\text { Wendi } \\
\text { Rabiner } \\
\text { Heinzelman, } \\
\text { Anantha } \\
\text { Chandrakasan } \\
\text {, and Hari } \\
\text { Balakrishnan[ } \\
\text { 13] }\end{array}$ & 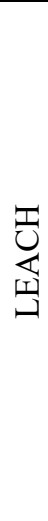 & $\begin{array}{l}\text { Random } \\
\text { selection } \\
\text { of cluster } \\
\text { head } \\
\text { based on } \\
\text { threshold }\end{array}$ & $\begin{array}{l}\text { Simple } \\
\text { to } \\
\text { impleme } \\
\text { nt }\end{array}$ & $\begin{array}{l}\text { the } \mathrm{CH} \\
\text { selection } \\
\text { is a } \\
\text { randomize } \\
\text { d process, } \\
\text { and the } \\
\text { remaining } \\
\text { energy of } \\
\text { the nodes } \\
\text { is not } \\
\text { considered } \\
\text { for the CH } \\
\text { selection }\end{array}$ \\
\hline $\begin{array}{l}\text { Jitendra } \\
\text { Singh, } \\
\text { Rakesh } \\
\text { Kumar, and } \\
\text { Ajai Kumar } \\
\text { Mishra[14] }\end{array}$ & 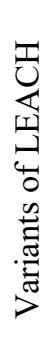 & $\begin{array}{l}\text { distributed } \\
\text { and hybrid } \\
\text { algorithms }\end{array}$ & $\begin{array}{l}\text { Perform } \\
\text { better } \\
\text { compare } \\
\text { d to } \\
\text { LEACH }\end{array}$ & $\begin{array}{l}\text { didn't } \\
\text { consider } \\
\text { all the } \\
\text { objectives } \\
\text { to give the } \\
\text { optimum } \\
\text { result for } \\
\text { CH } \\
\text { selection. }\end{array}$ \\
\hline
\end{tabular}




\begin{tabular}{|c|c|c|c|c|}
\hline $\begin{array}{l}\text { Vipin pal et } \\
\text { al.[15] }\end{array}$ & 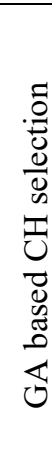 & $\begin{array}{l}\text { centralize } \\
\text { d } \\
\text { clustering } \\
\text { algorithms }\end{array}$ & $\begin{array}{l}\text { improve } \\
\mathrm{d} \text { the } \\
\text { network } \\
\text { lifetime } \\
\text { compare } \\
\mathrm{d} \text { to } \\
\text { tradition } \\
\text { al } \\
\text { LEACH } \\
\text { protocol } \\
\mathrm{s}\end{array}$ & $\begin{array}{l}\text { the } \\
\text { heterogene } \\
\text { ity of } \\
\text { nodes is } \\
\text { not } \\
\text { considered } \\
\text { and delay } \\
\text { increases } \\
\text { with the } \\
\text { increase of } \\
\text { population }\end{array}$ \\
\hline $\begin{array}{l}\text { Tripti Sharma } \\
\text { et al.[16] }\end{array}$ & $\begin{array}{l}\text { D } \\
0 \\
\tilde{0} \\
0 \\
0 \\
0\end{array}$ & $\begin{array}{l}\text { global } \\
\text { optimum } \\
\text { solution in } \\
\text { a complex } \\
\text { search }\end{array}$ & $\begin{array}{l}\text { increase } \\
\mathrm{s} \text { the } \mathrm{CH} \\
\text { energy } \\
\text { and } \\
\text { throughp } \\
\text { ut } \\
\end{array}$ & $\begin{array}{l}\text { Data is } \\
\text { directly } \\
\text { transmitte } \\
\mathrm{d} \text { to BS }\end{array}$ \\
\hline $\begin{array}{l}\text { Gai-Ge Wang } \\
\text { et al. [22] }\end{array}$ & $\underset{1}{3}$ & $\begin{array}{l}\text { Optimizati } \\
\text { on } \\
\text { algorithm } \\
\text { based on } \\
\text { two } \\
\text { reproducti } \\
\text { on types } \\
\text { of } \\
\text { earthwor } \\
\mathrm{ms}\end{array}$ & $\begin{array}{l}\text { Perform } \\
\text { s well } \\
\text { compare } \\
\text { d to GA, } \\
\text { PSO, } \\
\text { BBO, } \\
\text { ACO to } \\
\text { benchma } \\
\text { rk } \\
\text { function } \\
\text { s }\end{array}$ & $\begin{array}{l}\text { Lack of } \\
\text { the } \\
\text { previous } \\
\text { history of } \\
\text { best } \\
\text { solutions } \\
\text { elected so } \\
\text { far in the } \\
\text { iterations }\end{array}$ \\
\hline
\end{tabular}

\section{FEWA for clustering and data routing in WSN}

This section extensively describes the implementation of the earthworm optimization and fractional calculus (FEWA) for $\mathrm{CH}$ selection and optimum route selection and data communication in the WSN. The rest of the chapter is as follows: chapter 2.1 reflects the method's network model and block diagram. Section 2.2 describes the energy model for WSN with energy consumption equations. Section 2.3 analyzes the $\mathrm{CH}$ selection of the WSN with the method based on the objective function and its algorithm. Section 2.4 represents the optimum route selection from $\mathrm{CHs}$ to the sink based on the fit factor.

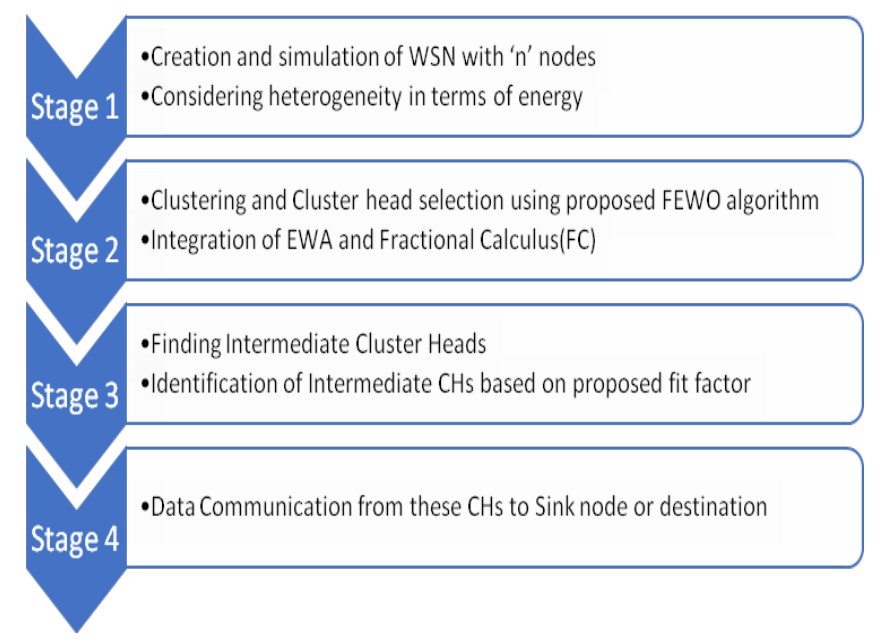

Figure 1. Block diagram of clustering and data communication in WSN

\subsection{Network model of WSN with FEWA}

In the method, it was assumed that in the $100 \times 100$ square sensor network area, there are 100 sensor nodes, and in the center of the region, there is a sink node or base station node. Based on the allocated $\mathrm{CH}$ probability, we assume $10 \mathrm{CH}$ nodes out of 100 sensor nodes in this work. The optimum selection of $\mathrm{CH}$ for these 10 nodes is modeled with the suggested algorithm. The final data communication from the $\mathrm{CHs}$ to the base station through some intermediate nodes. According to The Fit Factor, these $\mathrm{CH}$ route nodes are chosen, which has the maximum value of the fit factor and is selected as the neighbouring node for the optimum route from $\mathrm{CH}$ nodes to the base station. Clustering and data communication using the FEWA algorithm is represented by the block diagram shown in Figure 1. All sensor nodes are supposed to be static at their predefined locations, and heterogeneity is included in the network by assigning some nodes as advanced nodes with original energy greater than ordinary nodes. All other nodes are assumed to have the same initial energy with a fixed communication range.

\subsection{WSN Energy Model}

This chapter discusses WSN's energy model. Energy dissipation is calculated based on free space and multipath propagation channels based on the source and destination node distance. When an ordinary sensor node sends the data packet, the energy dissipation model is based on the following model,

$$
\begin{aligned}
& E_{d}(i)=E_{e l} \times b+E_{p a} \times b \times d^{4} ; \text { if } d \geq d_{0} \\
& E_{d}(i)=E_{e l} \times b+E_{f s} \times b \times d^{2} ; \text { if } d \leq d_{0}
\end{aligned}
$$




$$
\begin{aligned}
d_{0} & =\sqrt{\frac{\varepsilon_{f s}}{\varepsilon_{p a}}} \\
E_{e l} & =E_{t}+E_{a g}
\end{aligned}
$$

Where $E_{d}(i)=$ energy dissipated at $i^{\text {th }}$ the node for transmitting $b$ data bits to the $j^{\text {th }} \mathrm{CH}$, which is at a distance $d$ from node i.

$E_{e l}=$ energy dissipation due to electronics in the circuit

$E_{p a}=$ energy dissipation by power amplifier at the transmitter side

$$
\begin{aligned}
& E_{f s}=\text { free space energy } \\
& d=\text { distance between } i^{\text {th }} \text { node and } j^{\text {th }} \mathrm{CH} \\
& E_{e l}=\text { transmitter energy } \\
& E_{a g}=\text { energy for data aggregation }
\end{aligned}
$$

\section{3. $\mathrm{CH}$ allocation with FEWA optimization method}

Clustering is one of the most effective procedures to enhance the energy-constrained sensor networks' network lifetime. The FEWA the sensor node cluster optimization algorithm integrates EWA optimization and the fractional concept. EWA optimization is used to choose the optimal $\mathrm{CHs}$ according to the equation's highest fitness value (5). Adding the fractional concept in EWA's position calculation, the $\mathrm{CHs}$ are selected by interpreting the best $\mathrm{CHs}$ obtained so far in the previous iterations. So, the clustering accuracy is enhanced, and the optimal $\mathrm{CH}$ selection is assured, extending the network's lifetime.

The below equation represents the objective function for the FEWA algorithm in the WSN environment for optimum cluster head selection

$$
F=\sum_{i=1}^{N}\left[E_{i_{N C}}+\left(200-D_{i_{N C}}\right)+T_{i_{N}}\right]
$$

where $E_{i_{N C}}=$ Energy required to transmit data from node to cluster head,

$D_{i_{N C}}=$ distance between a node to cluster head,

$T_{i_{N}}=$ trust of the node computed using satisfaction, similarity, and feedback

The $\mathrm{CH}$ is selected as the node with the highest function value, and the suggested FEWA optimization algorithm follows this evaluation protocol. The energy of the node is modified based on the energy equations.

\subsection{Testing of FEWA algorithm}

FEWA optimization algorithm is tested with some standard objective functions like Ackely, Schwefel,
Rastrigin and Rosenbrock. It was tested with minimization of the cost function simulated for 100 functional evolutions. The FEWA algorithm gives better depreciation compared to the existing EWA, PSO and GA.

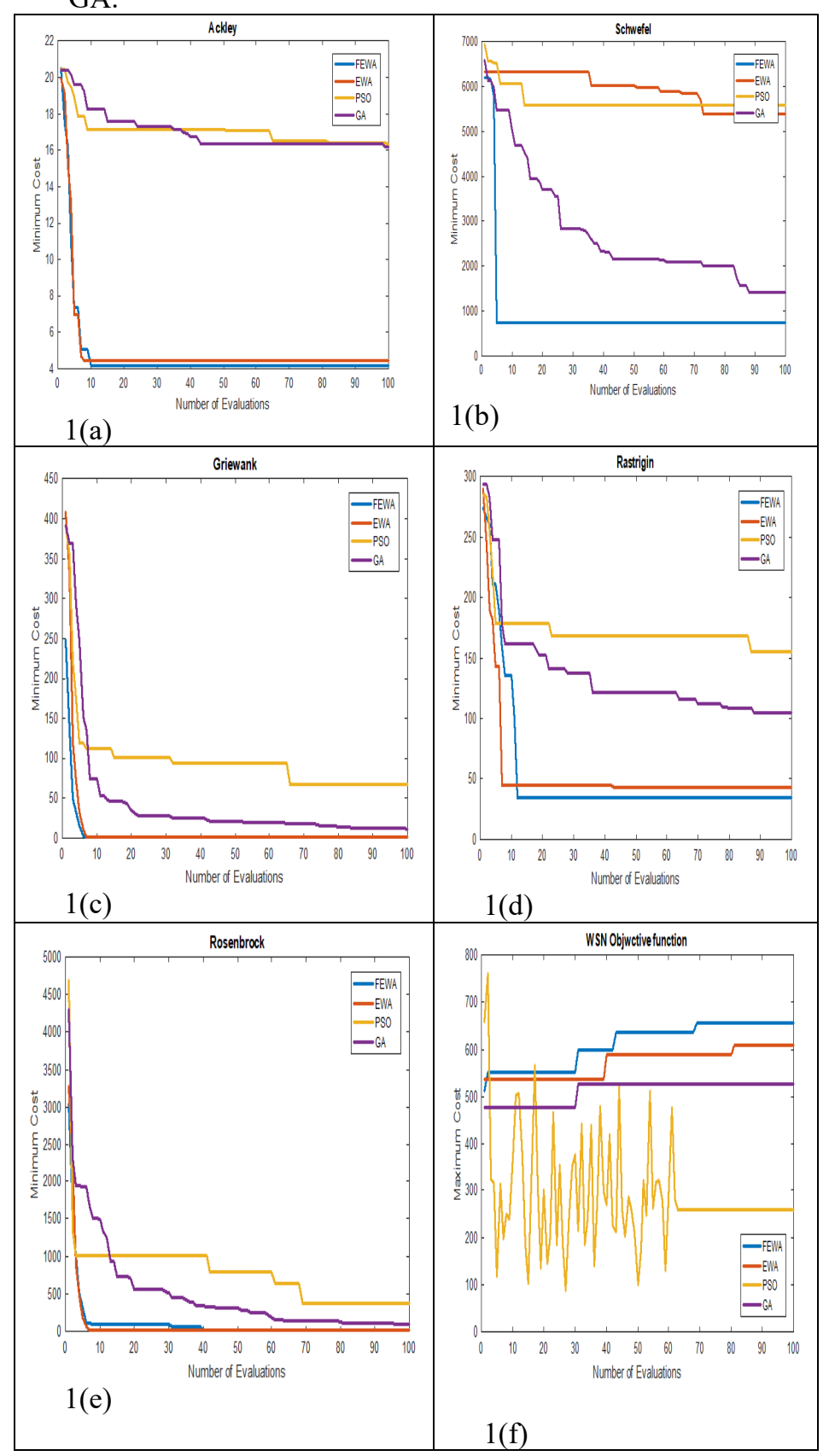

Figure 2. Convergence curves for different standard objective functions for all competing methods: 1a) Minimum Cost for Ackley, 1b) Minimum Cost for Schwefel, 1c) Minimum Cost for Griewank,1d) Minimum Cost for Rastrigin, 1e) Minimum Cost for Rosenbrock, 1e) Maximum Cost for WSN objective function 
FEWA also tested with the WSN objective function defined for our work and compared it with other optimization algorithms. From Figure 2, it was found that the FEWA algorithm gives better optimization results compared to other optimization algorithms. The objective function proposed in the WSN is a maximization function, and the optimization requirement is to maximize the cost function, as shown in table 2.

Table 2. Minimum Cost values for competing methods for different standard objective functions

\begin{tabular}{|l|l|c|c|c|}
\hline \multicolumn{5}{|c|}{ Minimum Cost Values } \\
\hline & FEWA & EWA & PSO & GA \\
\hline Schwefel & 737.7705 & 5395.614 & 5588.1 & 1422.894 \\
\hline Rosenbrock & 15.68308 & 22.18178 & 378.3907 & 90.33895 \\
\hline Rastrigin & 34.87853 & 43.14979 & 156.0612 & 104.7874 \\
\hline Griewank & 1.879116 & 2.128162 & 67.24282 & 11.44927 \\
\hline Ackley & 4.186098 & 4.45219 & 16.28359 & 16.1992 \\
\hline
\end{tabular}

\subsection{Optimum $\mathrm{CH}$ selection algorithm using FEWA algorithm}

FEWA is the EWA modification by adding the fractional concept to the final optimization equation to enhance the optimum selection of CHs. Fraction theory is used in the algorithm to update the $\mathrm{CH}$ selection based on the history of CHs selected in the previous iterations. The accuracy in clustering and the lifetime of the network can be increased. EWA is developed based on the two types of earthworm breeding in nature. The offsprings generated from these two types are subjected to weighted summation to produce the final child earthworm. The Cauchy mutation operator is used to increase the search space and avoid local optimum. The two kinds of reproduction types are modelled as follows:

Reproduction 1:

Since earthworms are hermaphrodites, so the offspring are produced by a single earthworm. The following equitation models the offspring produced from the reproduction 1

$$
x_{g 1, i}=x_{\max , i}+x_{\min , i}-\alpha x_{g, i}
$$

where $\mathrm{x}_{\mathrm{g}}$, $\mathrm{i}$ is the $\mathrm{i}^{\text {th }}$ element of the earthworm $\mathrm{x}_{\mathrm{g}}$, which indicated the earthworm $\mathrm{g}$ and $x_{g 1, i}$ represented the $\mathrm{i}^{\text {th }}$ element of the newly generated offspring earthworm $\mathrm{g} 1$. $\mathrm{x}_{\max }$ and $\mathrm{x}_{\min }$ are the upper and lower limits of the earthworm position and $\alpha$ is a similarity variable between 0 and 1 that determines the distance between the earthworm and the freshly reproduced earthworm.

Reproduction 2:

More than one offspring is generated from certain earthworms modelled as reproduction system 2 , a specific earthworm reproduction scheme. In this reproduction type, three different cases are considered by changing the number of parents (P) and the number of offsprings generated $(G)$. These three cases are analyzed by changing different improved cross over operations for better optimization processes such as single point crossover, uniform crossover, and multipoint crossover operations. Among all these improved operations, earthworm optimization gives better optimization for uniform crossover operation with case $\mathrm{P}=2$ and $\mathrm{G}=2$, which is considered in this algorithm.

For this uniform crossover operation, the two offsprings are generated by equation (7)

$$
\begin{aligned}
& x_{12, i}=P_{1, i} ; x_{22, i}=P_{2, i} \text { if } \text { rand }>0.5 \\
& x_{12, i}=P_{2, i} ; x_{22, i}=P_{1, i} \text { elsewhere }
\end{aligned}
$$

Where, $x_{12, i}$ and $x_{22, i}$ are the $\mathrm{i}^{\text {th }}$ component of the two offsprings generated \& $P_{1, i}, P_{2, i}$ are the two selected parents' ith elements for uniform crossover operation.

The earthworms generated for the reproduction 2 can be calculated by the equation (8)

$$
x_{g 2}= \begin{cases}x_{12} & \text { rand }<0.5 \\ x_{22} & \text { else }\end{cases}
$$

The weighted summation of the two offsprings provided by equation (9) determines the newly produced earthworm from reproduction 2 .

$$
x_{g 2}=w_{1} x_{12}+w_{2} x_{22}
$$

where $\mathrm{w} 1$ and $\mathrm{w} 2$ are the weight factors and can be obtained by the two offsprings' fitness values $x_{22}$.

Whenever the two reproduction types are implemented, the final position of the earthworm in the next generation is determined by the equation (10)

$x_{g}{ }^{t+1}=\beta x_{g 1}+(1-\beta) x_{g 2}$

The proportionality constant adjusts the proportional distance between two earthworms generated from two kinds of reproduction systems. This value is modified to the number of iterations to balance between local and global search. The above equation can be rewritten as

$x_{g}{ }^{t+1}-x_{g}{ }^{t}=\beta x_{g 1}+(1-\beta) x_{g 2}-x_{g}{ }^{t}=D^{\theta}\left[x_{g}{ }^{t+1}\right]$

From the fractional calculus[17], the differential term in a discrete-time implementation can be represented by fractional derivative given by

$$
D^{\theta}[y(t)]=\frac{1}{T^{\theta}} \sum_{h=0}^{r} \frac{(-1)^{k} \Gamma(\theta+1) y(t-h T)}{\Gamma(h+1) \Gamma(\theta-h+1)}
$$

Equation (11) can be considered as the differential term, and this differential term can be represented by the fractional derivative mentioned in equation (12).

Applying the above fractional derivative term to the equation (11) and expanding it into $r=4$ terms and then formulated as 
$D^{\theta}\left[x_{g}{ }^{t+1}\right]=x_{g}{ }^{t+1}-\theta \cdot x_{g}{ }^{t}-\frac{1}{2} \theta \cdot x_{g}{ }^{t-1}-\frac{1}{6}(1-\theta) \cdot x_{g}{ }^{t-2}-\frac{1}{24} \theta(1-\theta)(2-\theta) \cdot x_{g}{ }^{t-3}$

Substituting the equation(13) in equation (11), the final updated position of the earthworm using the FEWA algorithm is determined as

$x_{g}^{t+1}=(\theta-1) \cdot x_{g}{ }^{t}+\frac{1}{2} \theta \cdot x_{g}{ }^{t-1}+\frac{1}{6}(1-\theta) \cdot x_{g}{ }^{t-2}+\frac{1}{24} \theta(1-\theta)(2-\theta) \cdot x_{g}^{t-3}+\beta x_{g 1}+(1-\beta) x_{g 2}$

Hence, from equation (14), the earthworm's position value is updated for every iteration. From the above equation, it is clear that the position's previous values can also be interpreted for deciding the best $\mathrm{CH}$ selection. Thus, from the FEWA optimization, $\mathrm{n} \mathrm{CHs}$ are selected for the nodes selected for the optimum route selection from $\mathrm{CHs}$ to base station transmission.

The flow chart for the FEWA algorithm is shown in figure 3 .

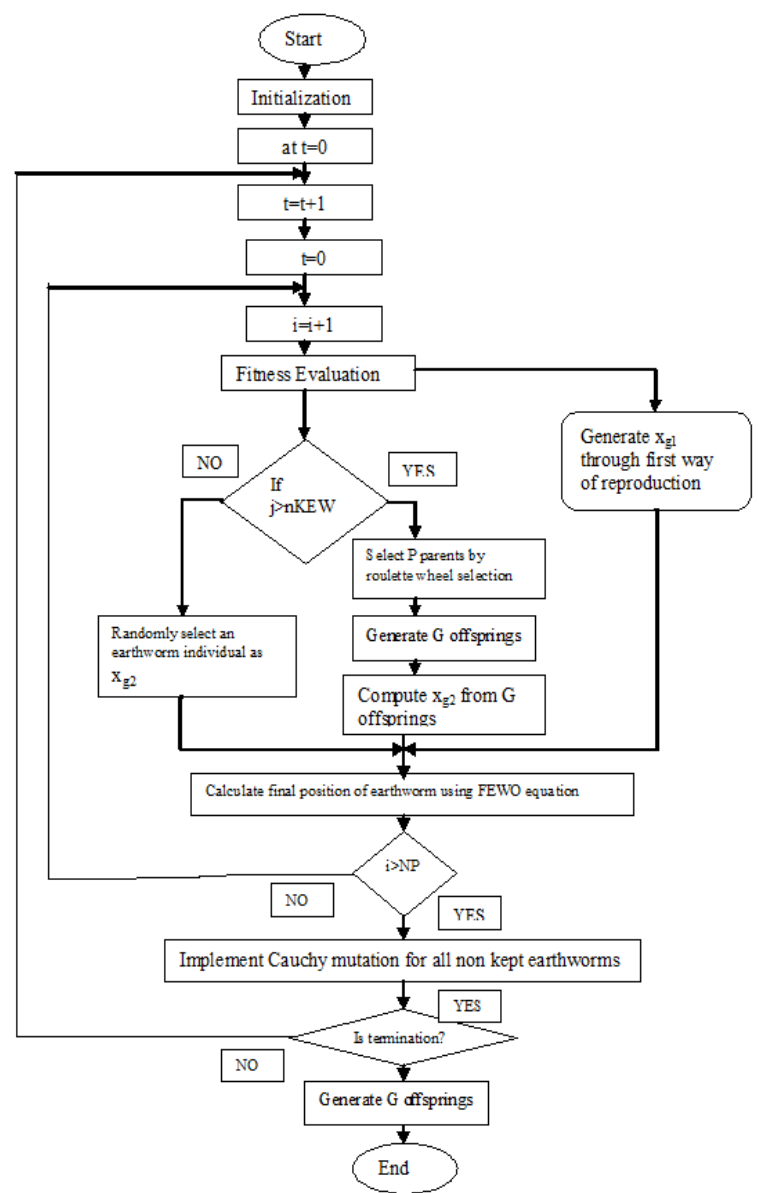

Figure 3. Flow chart for FEWA method's pseudo code

\subsection{Optimal Route selection based on the Fit factor}

Once the cluster head node is selected from the FEWA algorithm based on the objective function, then the cluster head's data must be communicated to the sink node in a multi-hop manner. So, the selection of the intermediate cluster heads is crucial for the routing path. Hence, to select the routes, route nodes are selected using the equation's fitness factor function (15). Therefore, the $\mathrm{CH}$ node with the highest fitness among the best cluster heads selected from FEWA is selected for the next routing path node.

The fitness factor function for choosing route cluster head node is designed based on energy, distance, and trust given as below

$$
F_{-} \text {factor }=\left[E_{n c}+\left(\frac{1-D_{n c}}{\sqrt{2 X_{m} Y_{m}}}\right)+T_{n c}\right]
$$

Where, $E_{n c}, D_{n c}$ and $T_{n c}$ are the energy, distance, and trust of the present cluster head node from the previous node. All these values are summed uo together for all the cluster head nodes to get the fitness function value.

\section{Results and Discussion}

The simulation results of the FEWA algorithm and comparative analysis with other optimization methods are presented in this section. The simulation environment is set up using MATLAB.

The WSN created in $100 \mathrm{~m}^{*} 100 \mathrm{~m}$ area after the implementation FEWA algorithm is mentioned in Figure 4 at a random number of rounds:

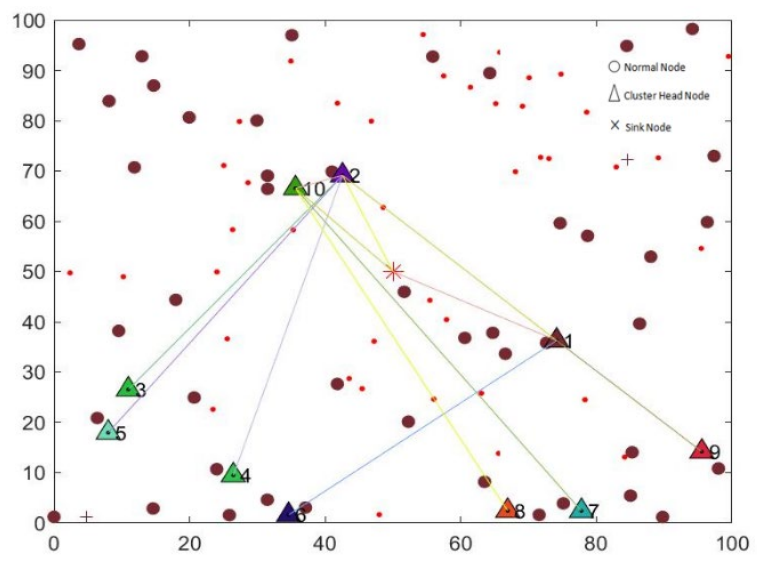

Figure 4. Simulation architecture of WSN created in $100 \mathrm{~m} * 100 \mathrm{~m}$ area using the method with 100 nodes in the simulation environment at round no.700

\subsection{Performance parameters for comparison}

The important constraints and performance parameters of wireless sensor network are residual energy remained in 
sensor node after completing all the rounds, delay, number of alive nodes at the end of last round and throughput of the network. These performance parameters are calculated by using the following expressions.

$$
\begin{aligned}
& \text { Energy }=\left\{\begin{array}{l}
\mathrm{E}_{\mathrm{i}}-\left[\left(E_{t x}+E_{d a}\right) \times 10^{3}+E_{a m p} \times 10^{3} \times\left(d^{4}\right)\right] ; \text { if } \mathrm{d}>\mathrm{d}_{0} \\
\mathrm{E}_{\mathrm{i}}-\left[\left(E_{t x}+E_{d a}\right) \times 10^{3}+E_{a m p} \times 10^{3} \times\left(d^{2}\right)\right] ; \text { if } \mathrm{d} \leq \mathrm{d}_{0}
\end{array}\right. \\
& \qquad \begin{array}{c}
\text { where } \mathrm{d}_{0}=\sqrt{\frac{\mathrm{E}_{\mathrm{fs}}}{\mathrm{E}_{\text {amp }}}} \\
\text { Number of alive nodes }=\# \text { nodes with Energy }>0 \\
\text { for the current round }
\end{array} \\
& \text { Overall Delay }=\frac{\text { time at which the packet is sent from node }}{\text { time it is revieved by sink node }} \\
& \% \text { of Throughput }=\frac{\text { Number of packets recieved at base staion node }}{\text { Number of packets sent to base station node }} \times 100
\end{aligned}
$$

All these performance parameters are compared for the proposed FEWO algorithm with other existing clusterbased optimization methods GA [18], PSO [19], DE [20], ACO [21], and EWO [22]. This method is simulated for different similarity factor values and different population sizes, and in comparative analysis, we choose $\alpha=0.64$ and population size $=30$.

\subsection{Comparative Discussion}

\subsubsection{Comparison in terms of number of alive nodes}

Figure 5 provides a comparison of the number of live nodes for the strategy with the number of rounds dependent on PSO, EWA-based clustering and GA-based clustering. At the end of the 700 round, 91 for FEWA and 81 for PSO, 52 for EWA, and 86 for GA are provided for nodes still alive with some residual energy. The following figure shows clearly, as the number of dead nodes is smaller than other approaches, the algorithm will improve the network's existence.

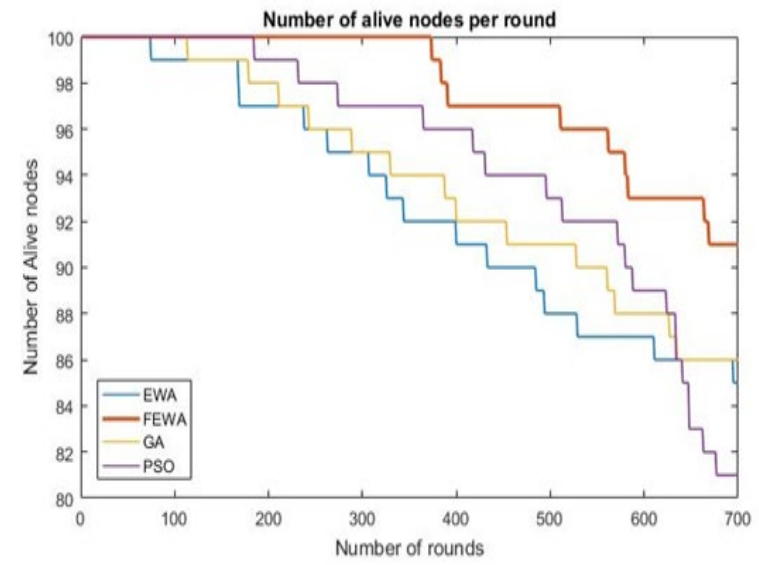

Figure 5. Comparative analysis of the number of nodes alive

\subsubsection{Comparison in terms of delay}

Figure 6 compares the delay value for the technique with the number of rounds with optimized clustering algorithms. At the end of the 1000 rounds, the delay evaluated by GA, PSO, DE, ACO, EWO, and proposed FEWA are $0.639 \mathrm{sec}, 0.583 \mathrm{sec}, 0.832 \mathrm{sec}, 0.604 \mathrm{sec}$, $0.433 \mathrm{sec}$, and $0.240 \mathrm{sec}$. The contrast curve below shows that the algorithm can do better with less delay than others so that more transmissions can be done in a given time.

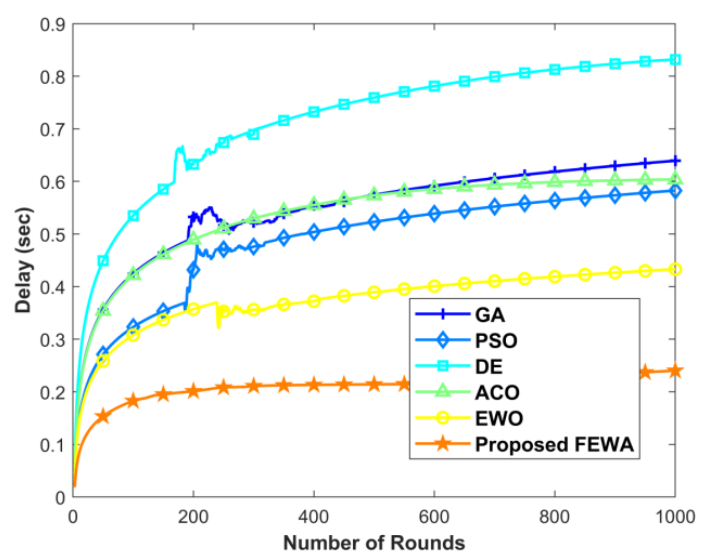

Figure 6. Comparative analysis of based on the overall delay

\subsubsection{Comparison in terms of throughput}

Figure 7 compares the throughput percentage value for the optimization-based clustering process to the number of rounds. At the conclusion of the 1000 rounds, the $\%$ of throughput values evaluated by GA, PSO, DE, ACO, EWO, and proposed FEWA are $0 \%, 0 \%, 0 \%, 0 \%, 0 \%$, and $10 \%$ respectively. From the graph, it is clear that the throughput is improved for the proposed method.

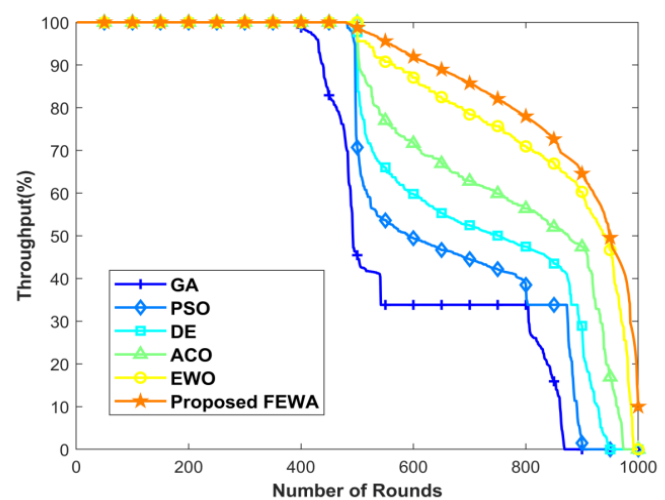

Figure 7. Comparative analysis based on throughput

\subsubsection{Comparison in terms of energy}

Figure 8 demonstrates the methodology's energy value relationships with other comparative methods in several rounds. At the end of the 1000 rounds, the energy evaluated by GA, PSO, DE, ACO, EWO, and proposed FEWA are $0 \mathrm{~J}, 0 \mathrm{~J}, 0 \mathrm{~J}, 0 \mathrm{~J}, 0 \mathrm{~J}$, and $0.019 \mathrm{~J}$. From the curve 
below, while the system's energy is smaller initially, but as the number of rounds increases, the residual energy at the end of the 1000 round is high relative to the other methods.

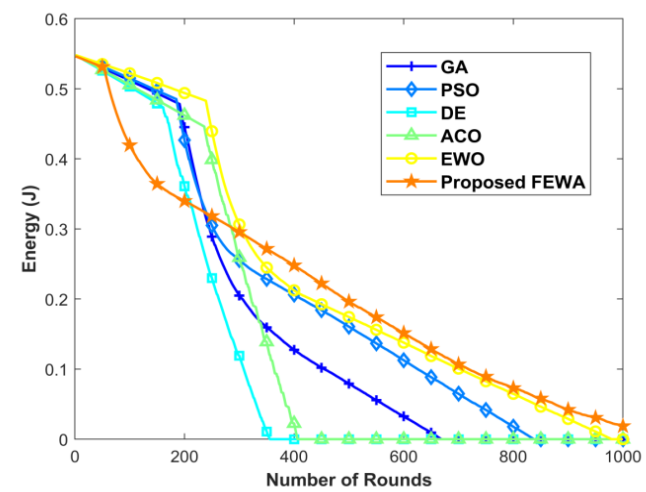

Figure 8. Comparative analysis of based on the overall delay

\subsubsection{Comparative discussion in terms of average values:}

The proposed FEWO method's performance is compared with other existing standard optimization algorithms after implementing them in our WSN scenario. The average values of performance parameters like delay, energy and throughput are mentioned in table 3 and table 4 with several nodes that are 50 and 100 .

Table 3. Comparison of FEWO algorithm with other optimization methods in terms of average values for 50 nodes

\begin{tabular}{|c|c|c|c|c|c|c|}
\hline \multirow{2}{*}{$\begin{array}{c}\text { Parame } \\
\text { ters }\end{array}$} & \multicolumn{6}{|c|}{ Number of nodes $=50$} \\
\cline { 2 - 7 } & GA & PSO & DE & ACO & EWO & $\begin{array}{c}\text { FEW } \\
\text { O }\end{array}$ \\
\hline $\begin{array}{c}\text { Delay } \\
\text { (sec) }\end{array}$ & $\begin{array}{c}0.276 \\
512\end{array}$ & $\begin{array}{c}0.402 \\
13\end{array}$ & $\begin{array}{c}0.482 \\
52\end{array}$ & $\begin{array}{c}0.326 \\
81\end{array}$ & $\begin{array}{c}0.220 \\
15\end{array}$ & $\begin{array}{c}0.082 \\
910\end{array}$ \\
\hline $\begin{array}{c}\text { Energy } \\
(\mathrm{J})\end{array}$ & $\begin{array}{c}0.179 \\
173\end{array}$ & $\begin{array}{c}0.146 \\
672\end{array}$ & $\begin{array}{c}0.137 \\
50\end{array}$ & $\begin{array}{c}0.184 \\
522\end{array}$ & $\begin{array}{c}0.220 \\
343\end{array}$ & $\begin{array}{c}0.330 \\
175\end{array}$ \\
\hline $\begin{array}{c}\text { Throug } \\
\text { hput } \\
(\%)\end{array}$ & $\begin{array}{c}64.86 \\
866\end{array}$ & $\begin{array}{c}68.35 \\
754\end{array}$ & $\begin{array}{c}72.41 \\
174\end{array}$ & $\begin{array}{c}77.81 \\
489\end{array}$ & $\begin{array}{c}85.79 \\
964\end{array}$ & $\begin{array}{c}87.80 \\
326\end{array}$ \\
\hline
\end{tabular}

Table 4. Comparison of FEWO algorithm with other optimization methods in terms of average values for 100 nodes

\begin{tabular}{|c|c|c|c|c|c|c|}
\hline \multirow{2}{*}{$\begin{array}{c}\text { Parame } \\
\text { ters }\end{array}$} & \multicolumn{7}{|c|}{ Number of nodes $=100$} \\
\cline { 2 - 7 } & GA & PSO & DE & ACO & EWO & $\begin{array}{c}\text { FEW } \\
\text { O }\end{array}$ \\
\hline $\begin{array}{c}\text { Delay } \\
\text { (sec) }\end{array}$ & $\begin{array}{c}0.547 \\
308\end{array}$ & $\begin{array}{c}0.486 \\
158\end{array}$ & $\begin{array}{c}0.715 \\
442\end{array}$ & $\begin{array}{c}0.537 \\
612\end{array}$ & $\begin{array}{c}0.374 \\
691\end{array}$ & $\begin{array}{c}0.208 \\
665\end{array}$ \\
\hline $\begin{array}{c}\text { Energy } \\
(\mathrm{J})\end{array}$ & $\begin{array}{c}0.165 \\
354\end{array}$ & $\begin{array}{c}0.202 \\
258\end{array}$ & $\begin{array}{c}0.124 \\
864\end{array}$ & $\begin{array}{c}0.153 \\
053\end{array}$ & $\begin{array}{c}0.232 \\
226\end{array}$ & $\begin{array}{c}0.216 \\
422\end{array}$ \\
\hline $\begin{array}{c}\text { Throug } \\
\text { hput } \\
(\%)\end{array}$ & 60.01 & 67.10 & 71.97 & 77.66 & 85.35 & 88.57 \\
61 & 725 & 621 & 661 & 704 & 683 \\
\hline
\end{tabular}

\section{Conclusion}

This paper presents the comparative analysis of the FEWA optimization method to integrate earthworm optimization algorithms with fractional calculus. The fractional derivative is used for calculating the position of the final earthworm after the two reproduction systems. By selecting the proportional constant 0.64 and the population size 30, the proposed Fractional Earth Worm Optimization algorithm (FEWA) is implemented in the WSN environment with 100 nodes and $100^{\times} 100$ square meter area with a sink node centre. The simulated results prove that the proposed algorithm gives better minimization for standard optimization functions. Further, the performance parameters like the number of alive nodes, residual energy, delay and throughput for the FEWO algorithm is compared with earlier reported optimization algorithms in the literature. This analysis shows that the implemented algorithm can perform well compared to the other standard optimization algorithms used in cluster head and routing techniques in wireless sensor networks. This work can be extended by implementing any hybrid optimization algorithm with multi-objective methods to further improve energy efficiency and network lifetime. The future extension of this research is to develop a hybrid optimization algorithm with fractional calculus. It would be interesting to recognize missing sensor data values in real-time environmental data using higher-order tensor completion models.

\section{References}

[1] Bushra Rashid and Mubashir Husain Rehmani, "Applications of WSNs for urban areas: A survey," Journal of Network and Computer Applications, 2015.

[2] Abdon Atangana, Aydin Secer, "A Note on Fractional Order Derivatives and Table of Fractional Derivatives of Some Special Functions," Abstract and Applied Analysis, vol. 2013.

[3] Venkat Rao Pasupuleti, Chinthaguntla Balaswamy, "Optimized routing and compressive sensing based data communication in wireless sensor network," IET Communications, vol. 14, no. 6, pp. 982 - 993, Apr. 2020, doi: 10.1049/iet-com.2019.0130.

[4] El Alami, Hassan, and Abdellah Najid. "Optimization of energy efficiency in wireless sensor networks and Internet of Things: A review of related works." Nature-Inspired Computing Applications in Advanced Communication Networks (2020): 89-127.

[5] Sharma, Manik, and Prableen Kaur. "A comprehensive analysis of nature-inspired meta-heuristic techniques for feature selection problem." Archives of Computational Methods in Engineering (2020): 1-25.

[6] Sharma, Samriti, and Gurvinder Singh. "Diagnosis of cardiac arrhythmia using Swarm-intelligence based Metaheuristic Techniques: A comparative analysis." EAI Endorsed Transactions on Pervasive Health and Technology 6.23 (2020) 
[7] Sharma, Manik, et al. "Analysis of DSS queries using entropy based restricted genetic algorithm." Applied Mathematics \& Information Sciences 9.5 (2015): 2599

[8] Kaur, Prableen, and Manik Sharma. "Analysis of data mining and soft computing techniques in prospecting diabetes disorder in human beings: a review." Int. J. Pharm. Sci. Res 9 (2018): 2700-2719.

[9] Agbehadji, Israel Edem, et al. "Review of big data analytics, artificial intelligence and nature-inspired computing models towards accurate detection of COVID19 pandemic cases and contact tracing." International journal of environmental research and public health 17.15 (2020): 5330.

[10] Singh, Rachhpal. "A gene expression data classification and selection method using hybrid meta-heuristic technique." EAI Endorsed Transactions on Scalable Information Systems 7.25 (2020).

[11] Singh, Rachhpal, and Rupinder Singh. "Nature Inspired Job Scheduling For E-Health Services In Mobile Cloud Computing." International Journal of Computer Applications \& Information Technology 11.

[12] Sharma, Samriti. "Applications of Genetic Algorithm in Software Engineering, Distributed Computing and Machine Learning." International Journal of Computer Applications and Information Technology, 9 (2017): 208212.

[13] W.R. Heinzelman, A. Chandrakasan, H. Balakrishnan, "Energy-efficient communication protocol for wireless microsensor networks," IEEE Proceedings of the 33rd annual Hawaii international conference on system sciences, vol. 2, 2000.

[14] Jitendra Singh, Rakesh kumar, Ajai Kumar Mishra, "Clustering algorithms for wireless sensor networks: A review," 2015 2nd International Conference on Computing for Sustainable Global Development (INDIACom), pp. 637-642, New Delhi 2015.

[15] Vipin Pal, Yogita, Girdhari Singhc, and R P Yadav, "Cluster Head Selection Optimization Based on Genetic Algorithm to Prolong Lifetime of Wireless Sensor Networks," Procedia Computer Science, Third International Conference on Recent Trends in Computing (ICRTC 2015), vol. 57, pp. 1417-1423, 2015.

[16] Tripti Sharma, G.S. Tomar, Brijesh Kumar, Ishaan Berry, "Particle Swarm Optimization based Cluster Head Election Approach for Wireless Sensor Network," International Journal of Smart Device and Appliance, vol. 2, no. 2, pp. 11-24, 2014.

[17] E. J. Solteiro Pires, J. A. Tenreiro Machado, P. B. de Moura Oliveira, J. Boaventura Cunha, and Luís Mendes, "Particle swarm optimization with fractional-order velocity," Nonlinear Dynamics, vol. 61, no. 1-2, pp. 295$301,2010$.

[18] Tadahiko Murata and HisaoIshibuchi, "Performance evaluation of genetic algorithms for flowshop scheduling problems", In Proceedings of the First IEEE Conference on Evolutionary Computation, IEEE World Congress on Computational Intelligence, pp. 812-817, June 1994.

[19] ShafiqAlam, GillianDobbie, YunSingKoh, PatriciaRiddle, and SaeedUrRehman, "Research on particle swarm optimization-based clustering: a systematic review of literature and techniques", Swarm and Evolutionary Computation, vol.17, pp.1-13, 2014.

[20] Arafa, M., Sallam, E.A. and Fahmy, M.M., "An enhanced differential evolution optimization algorithm", In 2014 Fourth International Conference on Digital Information and Communication Technology and its Applications (DICTAP) (pp. 216-225). IEEE, May 2014.

[21] TulinInkayaa, Sinan Kayalıgil, and Nur EvinOzdemirel, "Ant colony optimization-based clustering methodology", Applied Soft Computing, vol.28, pp.301-311, 2015.

[22] Gai-Ge Wang, Suash Deb, Leandro Coelho, "Earthworm optimization algorithm: a bio-inspired metaheuristic algorithm for global optimization problems," International Journal of Bio-Inspired Computation, 2015, doi: 10.1504/IJBIC.2015.10004283.

[23] Pandya, S.; Ambient Acoustic Event Assistive Framework for Identification, Detection, and Recognition of Unknown Acoustic Events of a Residence, Advanced Engineering Informatics, Elsevier. (http://www.sciencedirect.com/science/article/pii/S147403 462030207X)

[24] Srivastava A, Jain S, Miranda R, Patil S, Pandya S, Kotecha K. 2021. Deep learning-based respiratory sound analysis for detection of chronic obstructive pulmonary disease. PeerJ Computer Science 7:e369 https://doi.org/10.7717/peerj-cs.369.

[25] Ghayvat, H.; Pandya, S.; Awais, M. ReCognizing SUspect and PredictiNg ThE SpRead of Contagion Based on Mobile Phone LoCation DaTa (COUNTERACT): A System of identifying COVID-19 infectious and hazardous sites, detecting disease outbreaks based on internet of things, edge computing and artificial intelligence, Sustainable Cities and Society.

[26] Pandya, S.; Ghayvat, H.; Sur, A.; Awais, M.; Kotecha, K.; Saxena, S.; Jassal, N.; Pingale, G. Pollution Weather Prediction System: Smart Outdoor Pollution Monitoring and Prediction for Healthy Breathing and Living. Sensors, 2020, 20, 5448. https://doi.org/10.3390/s20185448. )

[27] Dilip Kumar Sharma, "Some Generalized Information Measures: Their characterization and Applications", Lambert Academic Publishing, Germany, 2010. ISBN: 978-3838386041.

[28] Pandya, S., Sur, A. and Kotecha, K., "Smart epidemic tunnel: IoT-based sensor-fusion assistive technology for COVID-19 disinfection", International Journal of Pervasive Computing and Communications, Emerald Publishing, 2020. https://doi.org/10.1108/IJPCC-07-20200091.

[29] D.S. Hooda and D.K. Sharma (2008), "Non-additive Generalized Measures of 'Useful' Inaccuracy" Journal of Rajasthan Academy of Physical Sciences, Vol. 7(3), 359368.

[30] Pandya S, Wakchaure MA, Shankar R, Annam JR. Analysis of NOMA-OFDM 5G wireless system using deep neural network. The Journal of Defense Modeling and Simulation. 2021. doi:10.1177/1548512921999108

[31] D.K. Sharma and D.S. Hooda (2010), "Generalized Measures of 'Useful' Relative Information and Inequalities" Journal of Engineering, Management \& Pharmaceutical Sciences, Vol.1(1), 15-21.

[32] Pandya, S.; Ghayvat, H.; Kotecha, K.; Awais, M.; Akbarzadeh, S.; Gope, P.; Mukhopadhyay, S.C.; Chen, W. Smart Home Anti-Theft System: A Novel Approach for Near Real-Time Monitoring and Smart Home Security for Wellness Protocol. Appl. Syst. Innov. 2018, 1, 42, MDPI. https://doi.org/10.3390/asi1040042.

[33] Awais, M.; Ghayvat, H.; Krishnan Pandarathodiyil, A.; Nabillah Ghani, W.M.; Ramanathan, A.; Pandya, S.; Walter, N.; Saad, M.N.; Zain, R.B.; Faye, I. Healthcare Professional in the Loop (HPIL): Classification of Standard and Oral Cancer-Causing Anomalous Regions of 
Oral Cavity Using Textural Analysis Technique in Autofluorescence Imaging. Sensors, 2020, 20, 5780. https://doi.org/10.3390/s20205780

[34] N. A. Jalil, H. J. Hwang, and N. M. Dawi, "Machines learning trends, perspectives and prospects in education sector," in ACM International Conference Proceeding Series, 2019.

[35] Patel, C.I.; Labana, D.; Pandya, S.; Modi, K.; Ghayvat, H.; Awais, M. Histogram of Oriented Gradient-Based Fusion of Features for Human Action Recognition in Action Video Sequences. Sensors 2020, 20, 7299. https://doi.org/10.3390/s20247299

[36] Ghayvat, H.; Awais, M.; Pandya, S.; Ren, H.; Akbarzadeh, S.; Chandra Mukhopadhyay, S.; Chen, C.; Gope, P.; Chouhan, A.; Chen, W. Smart Aging System: Uncovering the Hidden Wellness Parameter for Well-Being Monitoring and Anomaly Detection. Sensors 2019, 19, 766. https://doi.org/10.3390/s19040766.

[37] N. A. Jalil and K. Kian Yeik, "Systems, design and technologies anxieties towards use of self-service checkout," in ACM International Conference Proceeding Series, 2019.

[38] Sur S., Pandya, S., Ramesh P. Sah, Ketan Kotecha \& Swapnil Narkhede, Influence of bed temperature on performance of silica gel/methanol adsorption refrigeration system at adsorption equilibrium, Particulate Science and Technology, Taylor and Francis, 2020. DOI: 10.1080/02726351.2020.1778145

[39] R. Arulmurugan and H. Anandakumar, "Early Detection of Lung Cancer Using Wavelet Feature Descriptor and Feed Forward Back Propagation Neural Networks Classifier," Lecture Notes in Computational Vision and Biomechanics, pp. 103-110, 2018. doi:10.1007/978-3-319-71767-8_9

[40] Barot, V., Kapadia, V., \& Pandya, S., QoS Enabled IoT Based Low Cost Air Quality Monitoring System with Power Consumption Optimization, Cybernetics and Information Technologies, 2020, 20(2), 122-140. doi: https://doi.org/10.2478/cait-2020-0021.

[41] Leo Willyanto Santoso, Bhopendra Singh, S. Suman Rajest, R. Regin, Karrar Hameed Kadhim (2021), "A Genetic Programming Approach to Binary Classification Problem" EAI Endorsed Transactions on Energy, Vol.8, no. 31, pp. 1-8. DOI: 10.4108/eai.13-7-2018.165523

[42] Sur, A., Sah, R., Pandya, S., Milk storage system for remote areas using solar thermal energy and adsorption cooling, Materials Today, Volume 28, Part 3, 2020, Elsevier, Pages 1764-1770, ISSN 2214-7853, https://doi.org/10.1016/j.matpr.2020.05.170.

[43] Haldorai and A. Ramu, "An Intelligent-Based Wavelet Classifier for Accurate Prediction of Breast Cancer," Intelligent Multidimensional Data and Image Processing, pp. 306-319.

[44] R. Regin, S. Suman Rajest and Bhopendra Singh, "Spatial Data Mining Methods Databases and Statistics Point of Views", Innovations in Information and Communication Technology Series, pp. 103-109, 28 February, 2021.

[45] H. Ghayvat, Pandya, S., and A. Patel, "Deep Learning Model for Acoustics Signal Based Preventive Healthcare Monitoring and Activity of Daily Living," 2nd International Conference on Data, Engineering and Applications (IDEA), Bhopal, India, 2020, pp. 1-7, doi: 10.1109/IDEA49133.2020.9170666

[46] Pandya, S., Shah, J., Joshi, N., Ghayvat, H., Mukhopadhyay, S.C. and Yap, M.H., 2016, November. A novel hybrid based recommendation system based on clustering and association mining. In Sensing Technology
(ICST), 2016 10th International Conference on (pp. 1-6). IEEE.

[47] Singla M.K., Gupta J., Nijhawan P., Ganguli S., Rajest S.S. (2020) Development of an Efficient, Cheap, and Flexible IoT-Based Wind Turbine Emulator. In: Haldorai A., Ramu A., Khan S. (eds) Business Intelligence for Enterprise Internet of Things. EAI/Springer Innovations in Communication and Computing. Springer, Cham

[48] S, D., \& H, A. (2019). AODV Route Discovery and Route Maintenance in MANETs. 2019 5th International Conference on Advanced Computing \& Communication Systems (ICACCS). doi:10.1109/icaccs.2019.8728456

[49] D Datta, S Mishra, SS Rajest, (2020) "Quantification of tolerance limits of engineering system using uncertainty modeling for sustainable energy" International Journal of Intelligent Networks, Vol.1, 2020, pp.1-8, https://doi.org/10.1016/j.ijin.2020.05.006

[50] Souvik Ganguli, Abhimanyu Kumar, Gagandeep Kaur, Prasanta Sarkar and S. Suman Rajest, "A global optimization technique for modeling and control of permanent magnet synchronous motor drive", Innovations in Information and Communication Technology Series, pp. 074-081, 28 February, 2021.

[51] Dr. Laxmi Lidiya. S. Suman, Rajest, "Correlative Study and Analysis for Hidden Patterns in Text Analytics Unstructured Data using Supervised and Unsupervised Learning techniques" in International Journal of Cloud Computing, International Journal of Cloud Computing, Vol. 9, No. 2/3, 2020 